\title{
Pneumocystis jirovecii Pneumonia and Other Infections in Idiopathic Inflammatory Myositis
}

\author{
Christopher A. Mecoli ${ }^{1}$ (D) - Sonye K. Danoff ${ }^{2}$ \\ Published online: 5 February 2020 \\ (C) Springer Science+Business Media, LLC, part of Springer Nature 2020
}

\begin{abstract}
Purpose of Review The management of patients with idiopathic inflammatory myositis (IIM) can be complex and challenging due to the myriad of complications they can experience. The continued use of corticosteroids, in addition to the rise of combination immunosuppressive therapy, has contributed to the ongoing concern for infection. Perhaps the most feared infection in IIM patients is Pneumocystis jirovecii pneumonia (PJP) given its infrequent occurrence yet high mortality. The field has been, and continues to be, without evidence-based guidelines to help clinicians determine which patients with IIM to prescribe prophylaxis. Herein, we review this literature to provide the clinician with an up-to-date view of infections in IIM.

Recent Findings In the past 5 years, a number of studies have been reported highlighting various infectious complications, which help us better understand their frequency and associated risk factors. In addition, data has been published on the potential harms of PJP prophylaxis, to better inform the risk/benefit of our decision-making.

Summary Infection remains a major contributor to morbidity and mortality in IIM. A better understanding of which patient subgroups are at risk for particular infections will inform optimal management strategies.
\end{abstract}

Keywords Inflammatory myositis · Antisynthetase syndrome $\cdot$ Immunosuppression $\cdot$ Infection $\cdot$ Pneumocystis jirovecii pneumonia

\section{Introduction}

Infection remains a paramount concern in the management of patients with idiopathic inflammatory myopathies (IIM), including polymyositis (PM), dermatomyositis (DM), and immune-mediated necrotizing myopathies (IMNM). Balancing the risks of infection from immunosuppression with the consequences of increased myositis disease activity continues to challenge physicians. In recent years, studies

This article is part of the Topical Collection on Inflammatory Muscle Disease

Sonye K. Danoff

sdanoff@jhmi.edu

Christopher A. Mecoli

cmecoli1@jhmi.edu

1 Division of Rheumatology, Johns Hopkins Medicine, Baltimore, MD, USA

2 Division of Pulmonary and Critical Care Medicine, Johns Hopkins Medicine, Baltimore, MD, USA continue to identify infection as a leading cause of morbidity and mortality in patients with IIM [1-4]. Our aim in this report is to provide an updated review of literature as it pertains to infections in IIM, with particular focus on Pneumocystis jirovecii pneumonia (PJP).

\section{The Magnitude of the Problem}

The incidence of infection and causative organisms varies greatly depending on the environment in which patients are studied, that is, intensive care unit (ICU) vs general ward vs the outpatient setting. In more acute settings (hospitals and ICUs), infections are remarkably common and carry a high morbidity. In a retrospective review of 102 Chinese IIM patients admitted to the ICU over an 8-year period, $68(67 \%)$ were diagnosed with an infection, which was the most common reason for admittance to the ICU. The most common infection site was the lung, with pneumonia accounting for over $85 \%$ of infections. Causative organisms were identified in 43 patients, the majority of which were opportunistic 
infections, the three most common being pulmonary aspergillosis, PJP, and cytomegalovirus (CMV) pneumonia [2]. Of note, $40 \%$ of the patients studied received IV pulse solumedrol in the month prior to admission, and $86 \%$ were on at least $0.5 \mathrm{mg} / \mathrm{kg}$ of daily prednisone.

The frequency of opportunistic infections in the abovementioned Chinese study was not observed in a US study examining hospitalization records for patients with DM/PM (Healthcare Cost and Utilization Project Nationwide Inpatient Sample) [4]. Over 15,000 hospitalizations of DM and PM patients were studied with an inpatient mortality of approximately 5\%. Infection was significantly associated with mortality in these IIM patients (OR 3.4, 95\% CI 2.9-4.0). The most common infections were pneumonia and bacteremia. Overall, $28 \%$ of myositis patients had an infection recorded during their hospitalization; the majority of which were bacterial. Approximately $2 \%$ of patients had a viral infection (HSV, VZV, CMV), $1 \%$ had an opportunistic fungal infection (candidiasis, Cryptococcus, histoplasmosis, and aspergillosis), and $<1 \%$ had a mycobacterial infection. The degree of immunosuppression patients received is not contained within the Nationwide Inpatient Sample and, thus, was not reported.

An outpatient study was performed on a French IIM population examining 279 IIM patients from three medical centers. Of the 279, 104 (37\%) developed an infection over a median follow-up of 36 months. The most common diagnosis was aspiration pneumonia. Of those patients who experienced an opportunistic infection, the authors identified an array of causative pathogens, including Candida albicans, PJP, aspergillus fumigatus and atypical mycobacterial organisms among others [5]. Another outpatient study examined the charts of IIM patients over a 10 -year period totaling 631 patients with neuromuscular disease (149 of which had dermatomyositis). Prior et al. report a $19 \%$ rate of infection over a 10-year period [6]. Pneumonia and sepsis were the two most common infections. Notably, approximately $1 / 3$ of patients had an opportunistic infection, the most common of which was varicella zoster (VZV).

In some of these studies, the authors sought to identify the magnitude of risk individual immunosuppressive agents confer on infection rates. In the same French study of 279 IIM patients, the authors examined which medications patients were taking at the time their infection was diagnosed. Comparing patients who developed an infection $(N=94)$ to those who did not $(N=185)$, they reported that methotrexate and IVIG were both statistically associated with infection, OR 2.12 (95\% CI 1.22-3.68) and OR 3.58 (95\% CI 2.06-6.25), respectively. Upon adjusting for other factors in multivariable regression (malignancy, myalgia, ventilator insufficiency, and esophageal involvement), only methotrexate was statistically associated with infection (OR 2.0, 95\% CI 1.1-3.66, $p=0.02$ ) [5]. Different results were obtained from Prior and colleagues, who reported in a time-to-event analysis that plasmapheresis (PLEX), mycophenolate, and corticosteroids were all statistically significantly associated with an increased risk of infection. The multivariable HRs after adjusting for disease, sex, age, and drug exposure were 1.31 (95\% CI 1.17-1.47, $p<0.0001)$ for corticosteroids, 1.77 (95\% CI 1.33-2.34, $p<0.0001)$ for PLEX, and 1.38 (95\% CI 1.07-1.77, $p=$ 0.012 ) for mycophenolate.

Taken together, a number of general statements can be made from these studies. For one, there appears to be consensus that infection remains a main driver of morbidity and mortality in IIM patients. The lung is the most common site of infection, and opportunistic infections are not infrequent. Given the heterogeneity of opportunistic infections reported, it would be prudent to cast a wide diagnostic net when evaluating a patient with IIM where infection is suspected, including viral PCR and fungal staining on biospecimens. It remains unclear which disease characteristics and specific immunosuppressants place a patient at highest risk. Given the lung is a common site of infection, factors such as interstitial lung disease and dysphagia seem likely to confer risk. Similarly, while prednisone use appears to be a risk factor for many infections, the risk of other disease-modifying anti-rheumatic drugs and biologics is less clear.

\section{Pneumocystis jirocevcii Pneumonia}

The incidence of PJP in PM/DM is uncommon, having been estimated at 3.6/100,000 patient-years [7]. Still, it remains a grave concern in patients with autoimmune and rheumatic diseases due to its high mortality rate, ranging from 33 to $60 \%$ depending on the cohort examined $[8,9]$. Despite these mortality rates, many rheumatologists and other healthcare providers do not routinely administer prophylaxis $[10,11]$. This is at least in part due to the lack of evidence-based guidelines to help clinicians appropriately provide prophylaxis.

A recent study reviewed published PJP recommendations for autoimmune diseases [12•] (Table 1). The majority of the studies recommended consideration of PJP prophylaxis based on similar factors including the absolute lymphocyte count (ALC), presence of lymphopenia, and corticosteroid dose/duration. Some studies advocated for considering other risk factors such as intrinsic lung disease and older age. The authors went on to perform a small case-control study of 11 patients with autoimmune disease who developed PJP (two of which had inflammatory myositis). Upon adjusting for corticosteroid use, they showed that lymphopenia remained a statistically significant independent risk factor $(p=0.02)$, suggesting this may be a risk factor regardless of whether the patient is on corticosteroids.

A population-based study from the USA examined PJP prophylaxis prescribing patterns in patients with vasculitis, 
Table 1 Adapted and modified with permission from Tadros et al. [12•]

\begin{tabular}{|c|c|c|c|c|c|c|}
\hline \multirow[t]{2}{*}{ Study Name } & \multicolumn{5}{|c|}{ Factors guiding PJP prophylaxis initiation in patients with systemic autoimmune rheumatic disease } & \multirow{2}{*}{$\begin{array}{l}\text { PJP prophylaxis } \\
\text { recommendation from study }\end{array}$} \\
\hline & Lymphopenia & $\begin{array}{l}\text { Lymphocyte } \\
\text { count cut off }\end{array}$ & Corticosteroids & $\begin{array}{l}\text { Corticosteroids dose and } \\
\text { duration }\end{array}$ & Other & \\
\hline Okade et al. & $\mathrm{X}$ & & & & Pulmonary fibrosis & $\begin{array}{l}\text { Suggest PJP prophylaxis in } \\
\text { patients with at least one } \\
\text { risk factors for PJP (ILD, } \\
\text { lymphopenia) }\end{array}$ \\
\hline Ogawa et al. & $\mathrm{X}$ & & $\mathrm{X}$ & $\geq 30 \mathrm{mg} /$ day prednisolone & & $\begin{array}{l}\text { PJP in patients at high risk for } \\
\text { PJP (medium- or high-dose } \\
\text { corticosteroids with an } \\
\text { immunosuppressant with } \\
\text { decreased ALC) }\end{array}$ \\
\hline Inokuma et al. & $\mathrm{X}$ & $\mathrm{ALC}<500 / \mu \mathrm{L}$ & $\mathrm{X}$ & $\begin{array}{l}\geq 1.2 \mathrm{mg} / \mathrm{kg} / \text { day } \\
\text { prednisolone or those } \\
\text { receiving corticosteriods } \\
\text { equivalent to } \\
\geq 0.8 \mathrm{mg} / \mathrm{kg} / \text { day along } \\
\text { with other } \\
\text { immunosuppressive } \\
\text { agents }\end{array}$ & Age $>50$ & $\begin{array}{l}\text { PJP in patients with age }>50 \\
\text { receiving corticosteriods as } \\
\text { described, or whose } \\
\mathrm{AlC}<500 \text { during } \\
\text { immunosuppressive } \\
\text { therapy. }\end{array}$ \\
\hline Sowden et al. & $\mathrm{X}$ & $\mathrm{CD} 4+<200$ & $\mathrm{X}$ & $\geq 15 \mathrm{mg}$ prednisolone/day & & $\begin{array}{l}\text { Perform CD4+ counts after } \\
1 \text { month of } \\
\text { immunosuppression in } \\
\text { patients who are on } \\
\text { steroids ( }>15 \mathrm{mg} \\
\text { prednisolone/day), } \\
>3 \text { months corticosteriods } \\
\text { treatment and total ALC } \\
<500 \text { cells } / \mathrm{mm}^{3} \text {. CD } 4 \\
\text { count }<200 \text { may warrant } \\
\text { the use of prophylaxis if } \\
\text { annual risk of PJP in these } \\
\text { patients is }>9 \%\end{array}$ \\
\hline $\begin{array}{l}\text { Park } \\
\text { et al./Winth- } \\
\text { rop and } \\
\text { Baddley }\end{array}$ & $\mathrm{X}$ & & $X$ & $\begin{array}{l}>30 \mathrm{mg} \text { prednisone for } \\
\geq 4 \text { weeks OR } \geq 15-30 \mathrm{mg} \\
\text { daily with one additional } \\
\text { risk factor (baseline } \\
\text { lymphopenia, low CD4, } \\
\text { cyclophosphamide use, } \\
\text { anti-TNF or rituximab use, } \\
\text { or initial steroid dose } \\
>60 \mathrm{mg} / \text { day) }\end{array}$ & $\begin{array}{l}\text { Cyclophosphamide, } \\
\text { TNFi, or } \\
\text { rituximab }\end{array}$ & $\begin{array}{l}>30 \mathrm{mg} \text { prednisone for } \\
\geq 4 \text { weeks OR } \geq 15-30 \mathrm{mg} \\
\text { daily with one additional } \\
\text { risk factors (baseline } \\
\text { lymphopenia, low CD4, } \\
\text { cyclophosphamide use, } \\
\text { anti-TNF or rituximab use, } \\
\text { or initial steroids dose } \\
<15 \mathrm{mg} / \text { day) }\end{array}$ \\
\hline
\end{tabular}

systemic lupus, and IIM. A total of 316 patients ( 72 of which had IIM) were followed for approximately $24 \pm 14$ months. During follow-up, not a single case of PJP was identified in this study. The study provides data on the adverse event rate due to prophylactic agents used by clinicians, with trimethoprim/sulfamethoxazole (TMP/SMX) being the most commonly $(73 \%)$ used prophylaxis followed by dapsone and atovaquone. The authors calculated an adverse event incidence rate of $2.2 \%$ per person-year (among 124 patients who received prophylaxis, 12 had an adverse event during the study period). Since this ascertainment was based on reported allergies in the electronic medical record for the adverse event rate, this is likely an underestimate [11].
A French study examined 129 patients who developed PJP, 27 of which had an autoimmune/inflammatory disorder and examined the absolute lymphocyte and CD4 count [13]. Of the 27 patients, $70 \%$ developed PJP with CD4 $>200 / \mathrm{mm}^{3}$, $50 \%$ with CD4 $>300$, and $25 \%$ with CD4 $>450$. Over $60 \%$ of patients developed PJP with absolute lymphocyte counts (ALC) $>600 / \mathrm{mm}^{3}$, and $18.5 \%$ developed PJP with ALC > $1200 / \mathrm{mm}^{3}$. The two patients with dermatomyositis who developed PJP both had ALC > 800 and CD4 $>500 / \mathrm{mm}^{3}$.

A large Korean study was performed to evaluate the use of TMP/SMX PJP prophylaxis in patients with a rheumatic disease [14]. A total of 1522 steroid treatment episodes (defined as steroid $\geq 30 \mathrm{mg}$ /day for $\geq 4$ weeks) in 1092 patients were 
studied over a 12 -year period. Of these treatment episodes, 262 were associated with TMP/SMX prophylaxis. Propensity score matching was utilized to account for differences between the two populations (group receiving prophylaxis versus group who did not). Expectedly, patients who received prophylaxis were more likely to be older, have lymphopenia, have a "high risk" rheumatic disease (granulomatosis with polyangiitis, microscopic polyangiitis, DM), and to be treated with secondary immunosuppressive agents. Thirty PJP cases were identified in 30 patients $(15 \mathrm{on} \geq 30 \mathrm{mg}$ /day prednisone, 12 on $15-30 \mathrm{mg} /$ day, and 3 cases $<15 \mathrm{mg} /$ day. The authors reported a dose responsiveness of PJP risk; the incidence rate ratio (vs 30-45 $\mathrm{mg}$ prednisone/day) was 2.26 for 45-60 mg/day and 3.35 for $\geq 60 \mathrm{mg} /$ day. The authors also reported that TMP/SMX was very effective (HR 0.17, 95\% CI 0.02-1.22) in preventing PJP. A valuable aspect about the work is the reporting of all adverse drug reactions which occurred in 34 patients (21.2/100 person-years), two of which were serious (pancytopenia and Stevens-Johnson syndrome). From this information, the authors were able to calculate the number needed to harm $(\mathrm{NNH})$ being 131, in contrast to the number needed to treat (NNT) to prevent one case of PJP, which was 52 .

Despite the study limitations (largely Korean cohort, use of daily single strength TMP/SMX as opposed to the more often prescribed thrice weekly double-strength dosing, imperfect matching of groups using propensity scoring), this work provides valuable information to inform clinicians' decisionmaking. In an accompanying editorial to the article by Park et al., Winthrop and Baddley proposed guidelines for patients with DM/PM [15]. Prophylaxis with TMP/SMX should be provided for patients on $>30 \mathrm{mg}$ prednisone for $\geq 4$ weeks, and also for those patients taking $15-30 \mathrm{mg}$ daily, provided they have at least one additional risk factor (baseline lymphopenia, low CD4, cyclophosphamide use, anti-TNF or rituximab use, or initial glucocorticoid dose of $>60 \mathrm{mg} /$ day). They also recommend discontinuing prophylaxis when the glucocorticoid dose drops below $15 \mathrm{mg}$ daily.

While these recommendations are welcome in this area of uncertainty, it must be said that for every proposed rule or guidelines, exceptions invariably exist. Along with other recommendations [15], including those suggested by Winthrop and Baddley, patients who receive steroids for $\geq 4$ weeks should be given PJP prophylaxis [16••]. However, reports exist of PJP occurring in patients $<4$ weeks after prednisone monotherapy [17]. Until prospective, controlled studies are performed investigating different PJP prophylaxis strategies, it is unlikely we will have adequate evidence to make confident recommendations. Additional data will be needed to understand the adverse event rate of PJP prophylaxis agents as was done by Schmajuk and Park et al. Only then will risk/benefit ratios be able to be calculated and an informed discussion with patients can be conducted. In our practice, patients with IIM are typically prescribed TMP/SMX for PJP prophylaxis with prolonged ( $>2$ weeks) prednisone use over $20 \mathrm{mg} /$ day. The discontinuation of TMP/SMX occurs when prednisone is less than $20 \mathrm{mg}$ and/or lymphopenia improves. We typically prescribe trimethoprimsulfamethoxazole DS three times per week or dapsone $100 \mathrm{mg}$ daily, the latter only after ensuring normal G6PD enzyme activity.

\section{Other Infections}

\section{Progressive Multifocal Leukoencephalopathy}

Despite the increasing use of high-dose mycophenolate and rituximab to treat IIM, relatively few cases of PML have been reported [18-21] (both mycophenolate and rituximab have been issued black box warnings for the development of PML). Importantly, a single case has been reported of a patient with untreated DM developing PML, suggesting immunosuppression may not always be required for PML to occur [22]. While IVIG is often considered "protective" for infectious complications due to passive immunity, at least 3 PML cases have been reported in IIM patients receiving IVIG in addition to other immunosuppressants [21]. While patients should be counseled on this potential and rare risk of medications, often it is judged that the potential benefits outweigh the risks.

\section{Varicella Zoster Virus}

One out of every three Americans will develop shingles during their lifetime, and of that group, 1 in 10 patients will develop post-herpetic neuralgia ( $\mathrm{PHN})$ that can last months or years [23]. Patients with IIM, even those not on therapy, are at higher risk for developing VZV compared with the general population [24]. With an increasing use of higher dose and combination immunosuppressant therapy, VZV continues to be challenge to physicians treating patients with IIM $[6,24]$.

A recent case-control Taiwanese study by Tsai et al. examined over 2000 patients with IIM and compared them to age, sex, and comorbidity-matched controls. Upon examining patients with IIM, those who developed VZV were significantly more likely to be receiving immunosuppressants $(50 \%$ vs $1.67 \%, p<0.0001$ and corticosteroids $75 \%$ vs $23 \%$, $p<0.0001)$. The adjusted hazards ratio for developing VZV in IIM patients compared with matched controls was 3.90 (95\% CI 3.18-4.77). The incidence rate for VZV per 1000 person-years was higher in IIM patients even if they were not on immunosuppressive therapy (28.7/1000 person-years) compared with matched controls (5.75/1000 person-years). In IIM patients on corticosteroids and immunosuppression, the incidence rate increased to $40.3 / 1000$ person-years [24]. 


\section{Vaccinations}

We recommend all patients receive Pneumovax-23 as well as Prevnar-13 given the likelihood they will receive immunosuppression. All patients should also receive the annual flu vaccine unless a contraindication is noted $[25,26]$. In 2006, the live attenuated shingles vaccine Zostavax ${ }^{\circledR}$ emerged to help prevent shingles and its complications. More recently, in 2017, a new dead virus vaccine called Shingrix ${ }^{\circledR}$ was released that is more than $90 \%$ effective in preventing shingles and $\mathrm{PNH}$, and is the preferred vaccine recommended by the Centers for Disease Control [23]. Adults over 50 are approved for the vaccine, and it is given in a two shot series, administered 2-6 months apart. Even if patients have had the original shingles vaccine (Zostavax ${ }^{\circledR}$ ) or shingles itself, they can still receive Shingrix ${ }^{\circledR}$. Unlike Zostavax, which is a weakened live virus, Shingrix uses a dead virus, so in theory, the use in immunosuppressed patients is safe.

\section{Conclusions}

Infection remains a major concern in the management of IIM. A better understanding of which patient subgroups are at risk for particular infections will inform future guidelines on who to prophylaxis and the optimal use of combination immunosuppressant therapy.

\section{Compliance with Ethical Standards}

Conflict of Interest The authors declare that they have no conflict of interest.

Human and Animal Rights and Informed Consent This article does not contain any studies with human or animal subjects performed by any of the authors.

\section{References}

Papers of particular interest, published recently, have been highlighted as:

- Of importance

•. Of major importance

1. Wu C, Wang Q, He L, Yang E, Zeng X. Hospitalization mortality and associated risk factors in patients with polymyositis and dermatomyositis: a retrospective case-control study. PLoS One. 2018;23:e0192491.

2. Peng JM, Du B, Wang Q, Weng L, Hu XY, Wu CY, et al. Dermatomyositis and Polymyositis in the intensive care unit: a single-center retrospective cohort study of 102 patients. PLoS One. 2016;26:e0154441.
3. Amaral Silva M, Cogollo E, Isenberg DA. Why do patients with myositis die? A retrospective analysis of a single-centre cohort. Clin Exp Rheumatol. 2016;34:820-6.

4. Murray SG, Schmajuk G, Trupin L, Lawson E, Cascino M, Barton $\mathrm{J}$ et al. A population-based study of infection-related hospital mortality in patients with dermatomyositis/polymyositis. Arthritis Care Res (Hoboken). 2015;67:673-80.

5. Marie I, Ménard JF, Hachulla E, Chérin P, Benveniste O, Tiev K, et al. Infectious complications in polymyositis and dermatomyositis: a series of 279 patients. Semin Arthritis Rheum. 2011;41:48-60. https://doi.org/10.1016/j.semarthrit.2010.08.003.

6. Prior DE, Nurre E, Roller SL, Kline D, Panara R, Stino AM, et al. Infections and the relationship to treatment in neuromuscular autoimmunity. Muscle Nerve. 2018;57:927-31. https://doi.org/10. 1002/mus.26032.

7. Fillatre P, Decaux O, Jouneau S, Revest M, Gacouin A, RobertGangneux F, et al. Incidence of Pneumocystis jiroveci pneumonia among groups at risk in HIV-negative patients. Am J Med. 2014;127:e11-7.

8. Falagas ME, Manta KG, Betsi GI, Pappas G. Infection-related morbidity and mortality in patients with connective tissue diseases: a systematic review. Clin Rheumatol. 2007;26:663-70.

9. Mecoli CA, Saylor D, Gelber AC, Christopher-Stine L. Pneumocystis jiroveci pneumonia in rheumatic disease: a 20-year single-centre experience. Clin Exp Rheumatol. 2017;35:671-3.

10. Cettomai D, Gelber AC, Christopher-Stine L. A survey of rheumatologists' practice for prescribing pneumocystis prophylaxis. J Rheum. 2010;37:792-9.

11. Schmajuk G, Jafria K, Evansa M, Shiboskic S, Gianfrancesco M, Izadi Z, et al. Pneumocystis jiroveci pneumonia (PJP) prophylaxis patterns among patients with rheumatic diseases receiving high-risk immunosuppressant drugs. Semin Arthritis Rheum. 2019;48:108792.

12. Tadros S, Teichtahl AJ, Wicks IP CS. Pneumocystis jirovecii pneumonia in systemic autoimmune rheumatic disease: a case-control study. Semin Arthritis Rheum. 2017;46:804-9 Provides a summary of different PJP prophylaxis recommendations from several other groups.

13. Baulier G, Issa N, Gabriel F, Accoceberry I, Camou F, Duffau P. Guidelines for prophylaxis of Pneumocystis pneumonia cannot rely solely on CD4-cell count in autoimmune and inflammatory diseases. Clin Exp Rheumatol. 2018;36:490-3.

14. Park JW, Curtis JR, Moon J, Song YW, Kim S, Lee EB. Prophylactic effect of trimethoprim-sulfamethaxazole for pneumocystis pneumonia in patients with rheumatic diseases exposed to prolonged high-dose glucocorticoids. Ann Rheum Dis. 2018;77:664-9.

15. Limper AH, Knox KS, Sarosi GA, et al. An official American Thoracic Society statement: treatment of fungal infections in adult pulmonary and critical care patients. Am J Respir Crit Care Med. 2011;183:96-128.

16.• Winthrop KL, Baddley JW. Pneumocystis and glucocorticoid use: to prophylax or not to prophylax (and when?); that is the question. Ann Rheum Dis. 2018;77:631-3 Provides context for prior PJP recommendations and puts forth another set of recommendations based both on evidence and expert opinion.

17. Viguier M, Fouéré S, de la Salmonière P, Rabian C, Lebbe C, Dubertret L, et al. Peripheral blood lymphocyte subset counts in patients with dermatomyositis: clinical correlations and changes following therapy. Medicine (Baltimore). 2003;82:82-6.

18. Vulliemoz S, Lurati-Ruiz F, Borruat FX, Delavelle J, Koralnik IJ, Kuntzer T, et al. Favourable outcome of progressive multifocal leucoencephalopathy in two patients with dermatomyositis. J Neurol Neurosurg Psychiatry. 2006;77:1079-82.

19. Molloy ES, Calabrese LH. Progressive multifocal leukoencephalopathy associated with immunosuppressive therapy 
in rheumatic diseases: evolving role of biologic therapies. Arthritis Rheum. 2012;64:3043-51.

20. Belhassen-Garcia M, Rábano-Gutiérrez A, Velasco-Tirado V, Romero-Alegria A, Pérez-Garcia ML, Martin-Oterino JA. Atypical progressive multifocal leukoencephalopathy in a patient with antisynthetase syndrome. Intern Med. 2015;54:519-24. https://doi.org/10.2169/internalmedicine.54.2748.

21. Dastmalchi M, Laki J, Lundberg IE, Iacobaeus E. Progressive multifocal leukoencephalopathy in a patient with polymyositis: case report and literature review. J Rheumatol. 2012;39:1299-303.

22. Gheuens S, Pierone G, Peeters P, Koralnik IJ. Progressive multifocal leukoencephalopathy in individuals with minimal or occult immunosuppression. J Neurol Neurosurg Psychiatry. 2010;81:24754.
23. Center for Disease Control and Prevention. https://www.cdc.gov/ shingles/index.html. Accessed 15 June 2019.

24. Tsai SY, Lin CL, Wong YC, Yang TY, Kuo CF, Cheng JM et al. Increased Risk of Herpes Zoster Following Dermatomyositis and Polymyositis: A Nationwide Population-Based Cohort Study. Medicine (Baltimore). 2015;94:e1138.

25. Center for Disease Control and Prevention. https://www.cdc.gov/ vaccines/vpd/flu/index.html. Accessed 15 June 2019.

26. Center for Disease Control and Prevention. https://www.cdc.gov/ vaccines/vpd/pneumo/index.html. Accessed 15 June 2019.

Publisher's Note Springer Nature remains neutral with regard to jurisdictional claims in published maps and institutional affiliations. 